classified according to their response to the initial dose of the "drug," their general clinical improvement, the duration of intravenous therapy and intragastric suction, and the frequency of complications. Overall results of the trial show that the Trasylol-treated patients did no better than the controls, and indeed may have fared worse. Although more Trasylol-treated patients had severe pancreatitis there was no difference in outcome at any grade of severity. The poor results with Trasylol could not be attributed to delay in starting therapy or to the age of the patient.

We are indebted to Farbenfabriken Bayer A.G., Leverkusen, Germany, who made a gift of Trasylol and the placebo. We would like to acknowledge with gratitude the help of the honorary surgeons of the Royal Prince Albert Hospital who made their patients available for inclusion in the trial. Finally, the study would not have been possible without the co-operation of the nursing and resident staff of the hospital, whose assistance is gratefully acknowledged.

\section{REFERENCES}

Beck, I. T., Kahn, D. S., Solymar, J., McKenna, R. D., and Zylberszac, B. (1964). Gastroenterology, 46, 531.

Forell, M. M. (1962). Germ. med. Mth., 7, 37.

Frey, (1963). Ann. N.Y. Acad. Sci., 104, 368. Stuttgart.

McCutcheon, A. D. (1963). Ann. Surg., 158, 233.

(1964). Aust. Ann. Med., 13, 174.

McHardy, G., Craighead, C. C., Balart, L., Cradic, H., and La Grange, C. (1963). 7. Amer. med. Ass., 183, 527.

Maurer, G. (1961). Med. Press, 246, 287.

Moshal, M. G., Marks, I. N., Bank, S., and Ford, D. A. (1963). S. Afr. med. $\mathscr{7} ., 37,1072$.

Nardi, G. L. (1963). New Engl. 7. Med., 268, 1065.

Thal, A. P., Kobold, E. E., and Hollenberg, M. J. (1963). Amer. Y. Surg., 105, 708 .

\title{
A Further Case of M.C.P.A. Poisoning
}

\section{H. R. M. JOHNSON,* M.A., M.B., B.CHIR., M.C.PATH., D.M.J. ; O. KOUMIDES, † B.SC., PH.D., F.R.I.C.}

Brit. med. F., 1965, 2, 629-630

M.C.P.A. (2-methyl-4-chlorophenoxyacetic acid) is one of the recently developed hormone weed-killers and is freely available without control. It is claimed that it has a low toxicity. A search of the literature has revealed only one fatal case (Popham and Davies, 1964). It was felt, therefore, that a further case of fatal poisoning by M.C.P.A. was worth recording.

\section{Case Report}

A retired blacksmith aged 65 was admitted in coma to Joyce Green Hospital, Dartford, at 2 p.m. on 24 July 1964 under the care of Dr. G. B. Stratton. He had a 40-year history of dyspnoea and cough with purulent sputum, and bronchiectasis of the right middle lobe had been diagnosed in 1958. He had had attacks of acute bronchitis and pneumonia on several occasions, the first as far back as 1924 .

In 1955 he developed auricular fibrillation, and had been treated for congestive cardiac failure with digoxin for the seven years prior to his death. He gave up his work as a blacksmith at the age of 61 and worked as a storeman for three years until his retirement in April 1964.

He had become depressed as a result of his increasing incapacity, and in 1955 attempted to take his life by an overdose of sleepingtablets. He was treated successfully and later transferred to a mental hospital for further treatment of his depression. Since his retirement he had remained depressed and his activities had become increasingly curtailed by breathlessness. His hobby was gardening, of which he was very fond, and his family said that "he didn't seem to be able to do his gardening as he used to," and this had aggravated his depression.

He was found unconscious at 12 noon on 24 July, slumped in the toilet, by his son-in-law, who had come to look for him as he had not appeared for lunch. There was an empty 2 -fl. oz. (57-ml.) bottle of Verdone weed-killer on the shelf in the toilet, and later an empty codeine-tablet bottle was found in his bedroom. He was transferred to hospital at 2 p.m. the same day.

On admission he was deeply unconscious and unresponsive to all stimuli. He had pinpoint pupils which did not react to light. He was sweating, and had a pulse rate of 64 and a blood-pressure of 80/60. Apart from extrasystoles his heart sounds were normal.

\footnotetext{
* Senior Lecturer, Department of Forensic Medicine, the London Hospital Medical College.

t Lecturer, Department of Forensic Medicine, the London Hospital Medical College.
}

There were multiple rhonchi throughout the chest with crepitations at the bases. Examination of the central nervous system showed almost absent reflexes with no asymmetry and extensor plantar responses. All the limbs were flaccid. He was incontinent of urine and facces. A lumbar puncture was not performed.

His stomach was washed out and he was given Methedrine (methylamphetamine hydrochloride) $30 \mathrm{mg}$., hydrocortisone 200 mg., and Lethidrone (nalorphine hydrobromide) $10 \mathrm{mg}$., the latter being repeated at 5 p.m.

By 8.30 p.m. his pulse rate was 92 and his blood-pressure 110/40, but by 1.30 a.m. the following day, $25 \mathrm{July}$, his blood-pressure had fallen to $80 / 60$ and he was not responding to Methedrine. He was sweating profusely, his pulse was weak, and his respirations had become rapid. His chest was sucked out and the hydrocortisone, Lethidrone, and Methedrine were repeated. A saline drip was begun. However, he remained deeply unconscious with a steadily falling blood-pressure, and he died at 8.30 a.m. on $25 \mathrm{July}, 20 \frac{1}{2}$ hours from the time he had been found unconscious.

\section{Necropsy Findings}

Necropsy was performed at 4 p.m. on 27 July. The body was that of a moderately well nourished man, with small blisters on the skin of the inner side of the right knee, right foot, and left shin. The brain was swollen but showed nothing else of note, and the cerebral arteries were free from atheroma. The lungs were bound down by old adhesions. There was congestion and oedema of all lobes, with emphysema of the apices and anterior borders of both lungs. The bronchi were greatly thickened and inflamed and contained pus. Those to the right middle and lower lobes were strikingly dilated and packed together with fibrosis of the lung parenchyma. There was no sign of pneumonia or pulmonary embolism. The heart was enlarged $(380 \mathrm{~g}$. $)$, with hypertrophy and dilatation of the right ventricle and dilatation of the right atrium. The pericardium and myocardium were healthy, the valves were competent, and there was only a mild degree of atheroma of the coronary arteries and aorta. The stomach contained $250 \mathrm{ml}$. of brown fluid. There were no obvious haemorrhages, or corrosion of the mucosa, but there was a chronic benign gastric ulcer $\frac{1}{2}$ in. $(1.3 \mathrm{~cm}$.) in diameter on the lesser curvature. The other organs were intensely congested but were otherwise unremarkable.

An extensive histological examination revealed evidence of severe chronic inflammation in the lungs with emphysema and fibrosis of the parenchyma with much carbon pigment, and thickening of the 
bronchi with irregularity and metaplasia of the epithelium and peribronchial lymphocytic infiltration. There were multiple foci of chronic inflammatory cells in the gastric submucosa and occasional multinucleated giant cells. The lesion was a chronic benign peptic ulcer. The other organs were within normal limits.

\section{Chemical Examination}

The structural formula of M.C.P.A. is represented as follows :

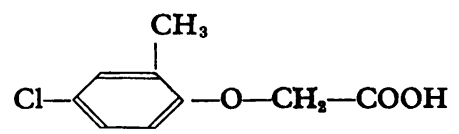

2-Methyl-4-chlorophenoxyacetic acid is determined spectrophotometrically in the ultra-violet at its maximum absorption at $280 \mathrm{~m} \mu$, after separation on column chromatography at $\mathrm{pH} 6.5$ (Curry, 1963).

Toxicological analysis was carried out on samples of blood, urine, and stomach contents removed at necropsy and on a sample of the gastric washings. M.C.P.A. was isolated from the above specimens after adding a small quantity of water and $10 \mathrm{ml}$. of $50 \%$ hydrochloric acid and extracted with two successive $50-\mathrm{ml}$. portions of chloroform (Henriet, 1955).

The combined chloroform extracts were shaken with $30 \mathrm{ml}$. of a saturated sodium bicarbonate solution. The chloroform layer was removed and extracted with $20 \mathrm{ml}$. of half-saturated solution of sodium bicarbonate. The combined bicarbonate extracts were neutralized with $1: 1$ hydrochloric acid, $10 \mathrm{ml}$. being added in excess, extracted once more with $50 \mathrm{ml}$. of chloroform, and the extraction repeated twice with two $30-\mathrm{ml}$. chloroform portions. The extract was filtered and digested at $100^{\circ}$ C., cooled, and made up to an appropriate volume.

The chromatography column was prepared by mixing carefully a quantity of Hyflo-Super-Cel with a buffer prepared after mixing 44 parts of a $3.45 \%$ solution of monosodium phosphate monohydrate and 56 parts of $3.55 \%$ of anhydrous disodium phosphate solution.

An aliquot of the extracted M.C.P.A. in chloroform was transferred to the $50-\mathrm{cm}$.-long and $20-\mathrm{mm}$.-diameter column containing the Hyflo-Super-Cel in equilibrium with the buffer for $p H$ 6.5.

M.C.P.A. was eluted with a $1: 1$ mixture of chloroform and acetone. The first $150 \mathrm{ml}$. was discarded, and the next $200 \mathrm{ml}$. of the mixed solvent was collected and evaporated to dryness. The amount of M.C.P.A. was taken up with $20 \mathrm{ml}$. of methanol and read at $280 \mathrm{~m} \mu$.

The quantities of M.C.P.A. recovered were:

\begin{tabular}{|c|c|c|c|c|}
\hline Blood & $\ldots$ & $0.018 \mathrm{~g} . / 100 \mathrm{ml}$ & Stomach & 0.017 \\
\hline Urine & $\ldots$ & 0.080 g. $/ 100 \mathrm{ml}$. & $\begin{array}{l}\text { Stomach } \\
\text { washings .. }\end{array}$ & $0.250 \mathrm{~g} . / 100$ \\
\hline
\end{tabular}

A calibration curve of M.C.P.A. was constructed from measurements on known amounts of M.C.P.A. which were analysed by the same procedure.

Salicylate analysis showed :

\begin{tabular}{lll|lll} 
Blood & $\ldots$ & $0.013 \mathrm{~g} . / 100 \mathrm{ml}$ & $\begin{array}{c}\text { Stomach } \\
\text { contents }\end{array}$ & $\ldots$ & $0.017 \mathrm{~g} . / 100 \mathrm{ml}$. \\
Urine & $\ldots$ & $0.038 \mathrm{~g} . / 100 \mathrm{ml}$. & $\begin{array}{c}\text { Stomach } \\
\text { washings }\end{array}$ & $\ldots$ & $0.008 \mathrm{~g} . / 100 \mathrm{ml}$.
\end{tabular}

Tests for barbiturates and codeine proved negative.

At the inquest evidence was forthcoming which indicated clearly that the taking of Verdone was a deliberate act, and a verdict of suicide while the balance of his mind was disturbed was returned by H.M. Coroner.

\section{Discussion}

There are certain points of similarity between this case and the case reported by Popham and Davies (1964). Both men had long-standing incapacitating respiratory disease and both survived about 20 hours. However, the previous case showed epileptiform features, with jerking of the eyes, twitching of the face, grand-mal convulsions, and opisthotonos, none of which occurred in the present case, although both patients had unreactive small pupils.
The inexorable downhill course, with falling blood-pressure, was the same in both cases. Profuse sweating occurred in our patient, and this may well have been due to the effects of salicylate, although only small quantities were recovered on analysis. The relatives thought that about 20 compound codeine tablets were missing from the bottle, equivalent to 80 gr. (5 g.) of aspirin, 80 gr. (5 g.) of phenacetin, and $2 \frac{1}{2}$ gr. $(0.16$ g.) of codeine phosphate. No other drug was in the house, and analysis for barbiturates was negative.

The active principle of Verdone is a $25 \%$ aqueous solution of M.C.P.A. as the potassium salt, and, assuming the patient drank the whole $2 \mathrm{fl}$. oz. ( $57 \mathrm{ml}$.), this would give a dose of about $250 \mathrm{mg} . / \mathrm{kg}$.

From animal experiments an $\mathrm{LD}_{50}$ of about $700 \mathrm{mg} . / \mathrm{kg}$. has been accepted ( $R$. Goulding, personal communication, 1964). In mice the $\mathrm{LD}_{50}$ is $500 \mathrm{mg} . \mathrm{kg}$. (Guseva, 1956). It may be that M.C.P.A. is more toxic to man than animal work suggests.

The symptoms described by previous workers (DalgaardMikkelsen and Poulsen, 1962) are undramatic, leading to coma and death. The related compound 2-4-dichlorophenoxyacetic acid (C.C.P.A.) also causes coma and death without convulsions (Curry, 1962).

The amounts of M.C.P.A. recovered in our case are comparable to the amounts recovered by the N.W. Forensic Science Laboratory in the case reported by Popham and Davies; allowance being made for the ingestion of $3 \mathrm{fl}$. oz. ( 85 $\mathrm{ml}$.) in their case and $2 \mathrm{fl}$. oz. (57 $\mathrm{ml}$.) in the present case.

Despite the severe respiratory disease, there can be no doubt that death was due to M.C.P.A. poisoning. A dose of $250 \mathrm{mg}$. $/ \mathrm{kg}$. which proved fatal casts doubt on the previously accepted belief that M.C.P.A. is of low toxicity, although it must be admitted that the long-standing chest disease would predispose towards a fatal outcome. The absence of any specific clinical feature makes the diagnosis impossible unless a clear indication-such as an empty bottle-is available.

It was felt that this case is worth reporting so as to draw attention to the possible dangers of M.C.P.A. and to give clinical, pathological, and toxicological details of a further fatal case of poisoning by this compound.

\section{Summary}

M.C.P.A. (2-methyl-4-chlorophenoxyacetic acid) is one of the recently developed hormone weed-killers reputedly of low toxicity that are freely available without restriction. Prior to the present case, only one report of a fatality due to M.C.P.A. had been published. A second fatal poisoning by this compound is described, with full clinical and pathological details and the method and result of toxicological analysis. The case concerned a 65-year-old retired blacksmith with chronic respiratory disease who in a fit of depression drank $2 \mathrm{fl}$. oz. $(57 \mathrm{ml}$.) of a commercial preparation of M.C.P.A. The literature is reviewed and the effects and toxicity of M.C.P.A. are discussed.

Our thanks are due to Mr. S. O. Matthews, H.M. Coroner for North-West Kent, for permission to publish ; to Dr. G. B. Stratton for clinical details; to Dr. R. Goulding, Director, the National Poisons Centre, for his advice and assistance; and to Professor F. E. Camps, Director, Department of Forensic Medicine, the London Hospital Medical College, for his advice and encouragement.

REFERENCES

Curry, A. S. (1962). Brit. med. f., 1, 687.

(1963). Poison Detection in Human Organs, pp. 41, 45. Thomas, Springfield, Illinois.

Dalgaard-Mikkelsen, Sv., and Poulsen, E. (1962). Pharmacol. Rev., 14, 225 .

Guseva, E. N. (1956). Farmakol. i Toksikol., 19, 41.

Henriet, J. (1955). Parasitica (Gembloux), 11, 81.

Popham, R. D., and Davies, D. M. (1964). Brit. med. F., 1, 677. 